\title{
Analisis Pengaruh Infrastruktur Listrik, Jalan Dan Kesehatan Terhadap Produk Domestik Regional Bruto Di Kabupaten Sidoarjo
}

\author{
Yurike Aldona, Wiwin Priana Primandhana, Muhammad Wahed \\ Program Studi Ekonomi Pembangunan, Fakultas Ekonomi dan Bisnis \\ Universitas Pembangunan Nasional "Veteran" Jawa Timur \\ Correspondence email: yurikealdona@gmail.com
}

\begin{abstract}
Abstrak. Produk Domestik Regional Bruto (PDRB) merupakan salah satu indikator ekonomi menurut berbagai instrument ekonomi yang didalamnya terlihat dengan jelas keadaan makro ekonomi suatu daerah. Infrastruktur merupakan prasarana publik paling primer dalam mendukung kegiatan ekonomi suatu negara, dan ketersediaan infrastruktur sangat menentukan tingkat efisiensi dan efektivitas kegiatan ekonomi. Penelitian ini bertujuan untuk menganalisis seberapa besar pangaruh infrastruktur listrik, jalan, dan kesehatan terhadap produk domestik regional bruto di Kabupaten Sidoarjo. Penelitian ini mencakup wilayah Kabupaten Sidoarjo. Penelitian ini menggunakan data sekunder yang diperoleh dari Badan Pusat Statistik dengan kurun waktu 15 tahun mulai tahun 2005-2019. Teknik analisis yang digunakan adalah Analisis Regresi Linier Berganda dengan model Ordinary Least Square $(O L S)$ menggunakan alat bantu komputer program SPSS (Statistic Program For Social Science) Versi 13.0 yang menunjukkan pengaruh antara variabel bebas dan variabel terikat. Hasil akhirnya adalah variabel infrastruktur listrik memiliki pengaruh yang positif dan signifikan terhadap produk domestik regional bruto di Kabupaten Sidoarjo. Variabel infrastruktur jalan dan infrastruktur kesehatan memiliki pengaruh yang positif tetapi tidak signifikan terhadap produk domestik regional bruto di Kabupaten Sidoarjo.
\end{abstract}

Kata Kunci: Infrastruktur Listrik, Jalan, Kesehatan, and GDP

\begin{abstract}
Gross Regional Domestic Product (GDP) is one of the economic indicators according to various economic instruments in which clearly visible macro-economic conditions of a region. Infrastructure is the most primary public infrastructure in supporting a country's economic activities, and the availability of infrastructure greatly determines the level of efficiency and effectiveness of economic activities. This study aims to analyze how much electricity, road, and health infrastructure affects gross regional domestic product in Sidoarjo Regency. This research covers the area of Sidoarjo Regency. This study uses secondary data obtained from the Central Statistics Agency with a period of 15 years from 2005-2019. The analysis technique used is Multiple Linear Regression Analysis with Ordinary Least Square (OLS) model using computer tools SPSS program (Statistic Program For Social Science) Version 13.0 that shows the influence between free variables and bound variables. The end result is that electricity infrastructure variables have a positive and significant influence on gross regional domestic product in Sidoarjo Regency. Variable road infrastructure and health infrastructure have a positive but insignificant influence on gross regional domestic product in Sidoarjo Regency.
\end{abstract}

Keywords: Electrical Infrastructure, Roads, Health, and GDP

\section{PENDAHULUAN}

Pembangunan ekonomi nasional merupakan upaya untuk membangun seluruh kehidupan masyarakat, bangsa dan negara untuk mewujudkan salah sa=tu tujuan nasional yaitu dengan cara memajukan kesejahteraan umum, seperti yang tertulis pada Pembukaan UUD 1945 Alinea IV (Lestari, 2019). Pembangunan sebagai salah satu cermin pengamalan Pancasila terutama dijiwai sila kelima, Keadilan Sosial Bagi Seluruh Rakyat Indonesia yaitu upaya peningkatan pembangunan dan hasilhasilnya menuju kepada tercapainya kemakmuran seluruh rakyat Indonesia (Kuncoro, 1997).

Salah satu indikator yang dapat melihat hasil pembangunan dalam suatu negara adalah pertumbuhan ekonomi. Pertumbuhan ekonomi merupakan kenaikan jangka panjang dalam kemampuan suatu negara untuk menyediakan semakin banyak jenis-jenis barang untuk memenuhi kebutuhan ekonomi kepada penduduknya, kemampuan ini tumbuh sesuai dengan kemajuan teknologinya dan penyesuaian kelembagaan dan ideologis yang diperlukan (Jhingan, 2008).
Dalam perspektif ini, pembangunan semestinya dapat memperluas akses publik untuk memperoleh sumber-sumber daya yang diperlukan guna mencapai kesejahteraan masyarakat, mempermudah akses publik untuk memperoleh dan menikmati berbagai fasilitas pelayanan dasar (pendidikan, kesehatan, air bersih, listrik, keamanan dan lain-lain), serta menjamin ketersediaan infrastruktur dan kontinuitas sumbersumber daya tersebut bagi kelangsungan hidup masyarakat (Maqin, 2011).

Pembangunan infrastruktur merupakan salah satu aspek penting dan vital untuk mempercepat proses pembangunan nasional maupun regional. Infrastruktur juga memegang peranan yang penting sebagai salah satu penggerak pertumbuhan ekonomi. Laju pertumbuhan ekonomi dan investasi suatu negara maupun daerah tidak dapat dipisahkan dari ketersediaan infrastruktur. Inilah yang menyebabkan infrastruktur menjadi pembangunan ekonomi yang berkelanjutan. Bertambahnya infrastruktur dan perbaikannya oleh pemerintah 
diharapkan memacu pertumbuhan ekonomi (Putro, 2011).

Laju pertumbuhan suatu daerah dapat di tunjukkan dengan Produk Domestik Regional Bruto (PDRB) (BPS, 2020). Pertumbuhan angka PDRB yang selalu positif juga ditunjukan oleh provinsi Jawa Timur dan Kabupaten Sidoarjo, berikut adalah Produk Domestik Regional Bruto menurut lapangan usaha atas dasar harga konstan 2010 Provinsi Jawa Timur dan Kabupaten Sidoarjo pada tahun 2015-2019:

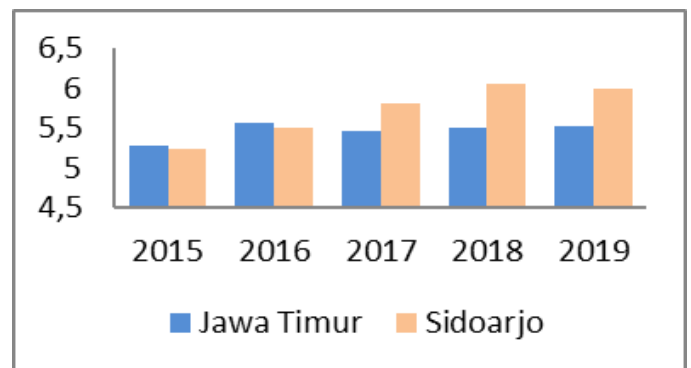

\section{Gambar 1 PDRB Provinsi Jawa Timur dan Kabupaten Sidoarjo}

Sumber: BPS Jawa Timur, 2020 (diolah)

Berdasarkan gambar diatas, angka PDRB Provinsi Jawa Timur mengalami fluktuasi setiap tahunnya, sedangkan PDRB Kabupaten Sidoarjo selalu mengalami peningkatan setiap tahunnya. Hal ini menggambarkan upaya pemerintah dalam meningkatkan kesejahteraan masyarakat melalui pendapatan per kapita. PDRB yang berperan sebagai pengukur tingkat pendapatan bruto yang berada dalam suatu daerah (Hapsari, 2011).

PDRB berpengaruh pada perekonomian dengan cara meredistribusi pendapatan bruto dan kekayaan serta menambah tingkat output. PDRB yang menurun akan menyebabkan ketidakpastian bagi pembanguanan di suatu daerah dan kesejahteraan masyarakatnya. Kegiatan perekonomian juga akan menurun dan mengakibatkan pendapatan nasional mengalami kemunduran serta pengangguran yang semakin bertambah dan merajanya kemiskinan.

Berdasarkan sejarah perjalanan pembangunan ekonomi, infrastruktur ditempatkan sebagai sektor vital dalam proses mencapai pertumbuhan ekonomi yang tinggi.

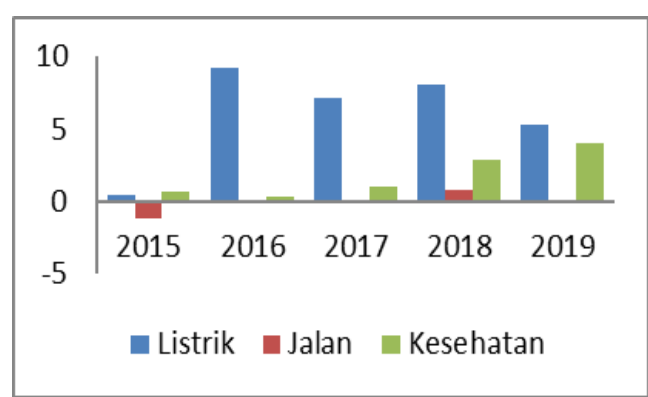

Gambar 2 Infrastruktur Listrik, Infrastruktur Jalan, dan Infrastruktur Kesehatan Kabupaten Sidoarjo 2015-2019 Sumber: BPS Jawa Timur, 2020 (diolah)
Berdasarkan gambar 2 secara umum, dapat digambarkan bahwa infrastruktur listrik mengalami fluktuasi setiap tahunnya, dengan mengalami kenaikan tertinggi pada tahun 2016 yaitu sebesar 9,24 persen. Sedangkan, infrastruktur jalan cenderung stabil dengan kenaikan 0,75 persen di tahun 2018. Lalu, infrastruktur kesehatan cenderung lebih meningkat setiap tahunnya dengan kenaikan tertinggi pada tahun 2019 sebesar 3,99 persen, hal ini dikarenakan adanya pembangunan fasilitas-fasilitas kesehatan yang dibutuhkan oleh masyarakat, sebagai penunjang angka harapan hidup.

\section{Landasan Teori}

\section{Konsep Infrastruktur}

Infrastruktur merupakan prasarana publik paling primer dalam mendukung kegiatan ekonomi suatu negara, dan ketersediaan infrastruktur sangat menentukan tingkat efisiensi dan efektivitas kegiatan ekonomi. Pembangunan infrastruktur adalah merupakan sesuatu yang seharusnya menjadi kewajiban Pemerintah. Menurut (Diwan, 2015) keberadaan infrastruktur sangat penting bagi pembangunan, sehingga pada tahap awal pembangunan disuatu negara hal tersebut akan dipikul sepenuhnya oleh Pemerintah, yaitu dari APBN murni.

\section{Infrastruktur Listrik}

Listrik merupakan energi terpenting dalam perkembangan kehidupan manusia modern, listrik digunakan untuk berbagai kegiatan baik di kota-kota besar maupun di wilayah pedesaan (Arindini, 2018). Kebutuhan akan energi listrik dari waktu ke waktu semakin meningkat seiring dengan pertumbuhan sosial didalam masyarakat. Tercukupinya pasokan akan listrik merupakan sebuah prasyarat bagi terselenggaranya kegiatan ekonomi karena listrik merupakan kebutuhan pokok dalam kehidupan sehari-hari dan hampir seluruh aktivitas masyarakat bergantung pada tenaga listrik.

\section{Infrastruktur Jalan}

Jalan merupakan salah satu infrastruktur keras yang berhubungan erat dengan pembangunan fasilitas umum berwujud fisik. Jalan juga merupakan sarana terpenting dalam adanya pembangunan dan penghubung antara manusia dengan kegiatan ekonomi, dengan adanya jalan dapat mempermudah akomodasi dalam pembangunan serta dapat merangsang pertumbuhan ekonomi (BPS, 2020).

\section{Infrastruktur Kesehatan}

(World Health Organization, 2013) mendefinisikan kesehatan sebagai sebuah kondisi kesejahteraan fisik, mental dan sosial, dan bukan sekedar bebas penyakit dan kelemahan fisik. Dalam prakteknya, pengukuran tingkat kesehatan yang digunakan antara lain tingkat harapan hidup. Ukuran ini merupakan salah satu dari tiga komponen dalam penghitungan Indeks Pembangunan Manusia (IPM). 


\section{Teori Pertumbuhan Ekonomi}

\section{Teori Pertumbuhan Ekonomi Klasik}

Menurut Adam Smith (Jhingan, 2008), ada dua hal yang menyebabkan terjadinya pertumbuhan ekonomi, yaitu pertumbuhan penduduk dan pembagian tugas para pekerja. Faktor yang terpenting adalah faktor pertumbuhan penduduk, karena dengan pertumbuhan penduduk cenderung akan meningkatkan produksi yang pada akhirnya akan mendorong adanya spesialisasi dan pembagian kerja pada tenaga kerja.

\section{Teori Pertumbuhan Neo Klasik}

Teori ini dikembangkan oleh Solow (Kuncoro, 1997). Menurut Teori pertumbuhan Neo-Klasik, pertumbuhan ekonomi tergantung pada penambahan persediaan faktor-faktor produksi dan tingkat kemajuan teknologi. Asumsi yang digunakan dalam teori SolowSwan adalah sebagai berikut (Situmorang, 2011):

1. Full Employment, karena bekerjanya mekanisme pasar

2. Teknologi dan populasi merupakan faktor eksogen

\section{Teori Pertumbuhan Ekonomi Modern}

Teori Pertumbuhan Ekonomi Modern, salah satunya pertumbuhan ekonomi Harrod-Domar dalam (Wibowo, 2016) menjelaskan bahwa dalam perekonomian pada dasarnya harus mencadangkan atau menyisihkan sebagian dari pendapatan nasionalnya untuk menambah atau mengganti barang-barang modal yang telah susut. Namun untuk memacu pertumbuhan ekonomi, dibutuhkan investasi baru yang merupakan tambahan netto terhadap stok modal maka dengan begitu setiap tambahan netto terhadap stok modal dalam bentuk investasi baru akan menghasilkan kenaikan arus output nasional atau GDP.

\section{Konsep Produk Domestik Regional Bruto (PDRB)}

Produk Domestik Regional Bruto (PDRB) merupakan salah satu indikator ekonomi menurut berbagai instrument ekonomi yang didalamnya terlihat dengan jelas keadaan makro ekonomi suatu daerah dengan pertumbuhan ekonominya, income perkapita dan berbagai instrument lainnya (Dewi \& Sutrisna, 2015).

Menurut data publikasi BPS Sidoarjo (BPS, 2020), PDRB dapat digunakan untuk mengetahui tingkat produk netto atau nilai tambah yang dihasilkan oleh seluruh faktor industri, laju pertumbuhan ekonomi, pola struktur perekonomian, dan perubahan indeks implisit.

\section{HIPOTESIS}

Hipotesis merupakan dugaan sementara yang masih perlu di uji kebenarannya melalui data-data yang diperoleh. Dengan mengacu pada dasar pemikiran yang bersifat teoritis dan berdasarkan studi empiris yang pernah dilakukan berkaitan dengan penelitian di bidang ini, maka akan diajukan hipotesis sebagai berikut:
1. Diduga Infrastruktur Listrik memiliki berpengaruh terhadap Produk Domestik Regional Bruto di Kabupaten Sidoarjo.

2. Diduga Infrastruktur Jalan memiliki berpengaruh terhadap Produk Domestik Regional Bruto di Kabupaten Sidoarjo.

3. Diduga Infrastruktur Kesehatan memiliki berpengaruh terhadap Produk Domestik Regional Bruto di Kabupaten Sidoarjo.

\section{METODE PENELITIAN}

\section{Jenis Penelitian}

Pendekatan ini menggunakan pendekatan kuantitatif, yaitu penelitian yang menekankan analisisnya pada data-data numerical (angka) yang diolah dengan metode statistika (Azwar, 2004). Penelitian ini dilakukan untuk menganalisis pengaruh infrastruktur listrik, jalan, dan kesehatan terhadap Produk Domestik Regional Bruto di Kabupaten Sidoarjo tahun 2005 sampai dengan 2019.

\section{Teknik Pengumpulan Data}

Data yang digunakan adalah jenis data sekunder, diperoleh dari instansi terkait, untuk mendapatkan suatu informasi, gambaran dan sebagai dasar teori dengan literatur jurnal, makalah, dan laporan yang terkait. Data diperoleh dari Badan Pusat Statistik (BPS) Jawa Timur dan Sidoarjo selama periode tahun 2005-2019.

\section{Teknik Analisis}

Teknik analisa data memakai analisis regresi linier berganda dengan model Ordinary Least Square (OLS). Analisis regresi linier berganda merupakan suatu metode yang digunakan untuk mengetahui ada atau tidaknya pengaruh variabel independen $\left(\mathrm{X}_{1}, \mathrm{X}_{2}, \mathrm{X}_{3}, \ldots \ldots, \mathrm{k}\right)$ terhadap variabel dependen (Y).

Persamaan Model Regresi Linier Berganda:

$\mathbf{Y}=\boldsymbol{\beta} 0+\boldsymbol{\beta}_{1} \mathbf{X}_{1}+\boldsymbol{\beta}_{2} \mathbf{X}_{2}+\boldsymbol{\beta}_{3} \mathbf{X}_{3}+\mathrm{e}$

Keterangan :

$\mathbf{Y}=$ Produk Domestik Regional Bruto (PDRB)

$\mathbf{X}_{\mathbf{1}} \quad=$ Infrastruktur Listrik

$\mathbf{X}_{\mathbf{2}} \quad=$ Infrastruktur Jalan

$\mathbf{X}_{\mathbf{3}} \quad=$ Infrastruktur Kesehatan

及0 = Konstanta (nilai $\mathrm{Y}$ apabila

$\mathrm{X}_{1}, \mathrm{X}_{2}, \mathrm{X}_{3}=0$ )

$\boldsymbol{\beta} \quad=$ Koefisien regresi (nilai peningkatan ataupun penurunan)

$\boldsymbol{e}=$ sisa (error)

\section{HASIL DAN PEMBAHASAN \\ Deskripsi Data}

Data Produk Domestik Regional Bruto (PDRB) 


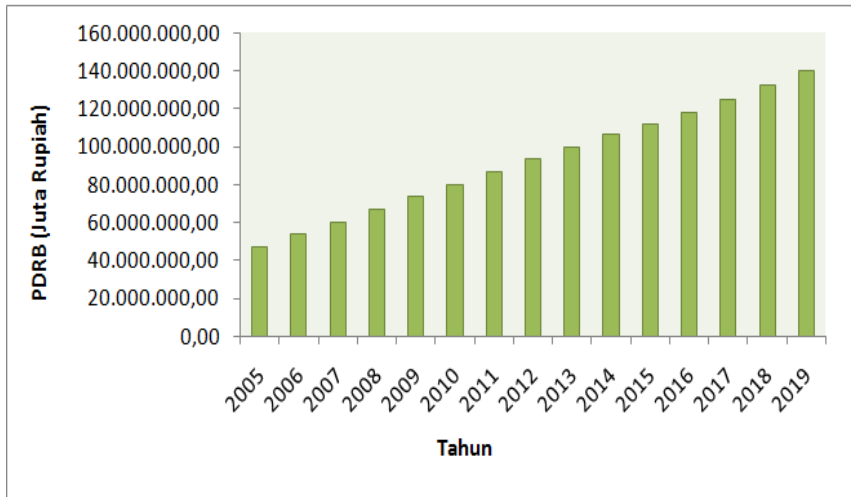

Gambar 3 Data Produk Domestik Regional Bruto (PDRB) Kabupaten Sidoarjo Tahun 2005-2019

Sumber: BPS Jawa Timur 2020 (data diolah)

Berdasarkan gambar diatas terlihat bahwa nilai Produk Domestik Regional Bruto di Kabupaten Sidoarjo pada tahun 2005-2019 termasuk dalam kategori yang cukup stabil, dengan rata-rata peningkatan sebesar Rp.93.222.757,93 juta/kapita. Perkembangan nilai PDRB tiap tahun Kabupaten Sidoarjo dari tahun 2005 sampai 2019 mengalami fluktuasi, selama kurun waktu 15 tahun nilai PDRB tertinggi yaitu tahun 2019 dengan nilai Rp.140.551.230,00 juta/ kapita, sedangkan angka yang terendah tahun 2005 sebesar Rp.47.447.848,44 juta/kapita. Peningkatan nilai Produk Domestik Regional Bruto di Kabupaten Sidoarjo dipengaruhi oleh nilai tambah yang dihasilkan seluruh faktor industri, laju pertumbuhan ekonomi, pola struktur perekonomian, serta bertambahnya fasilitas infrastruktur.

\section{Data Infrastruktur Listrik}

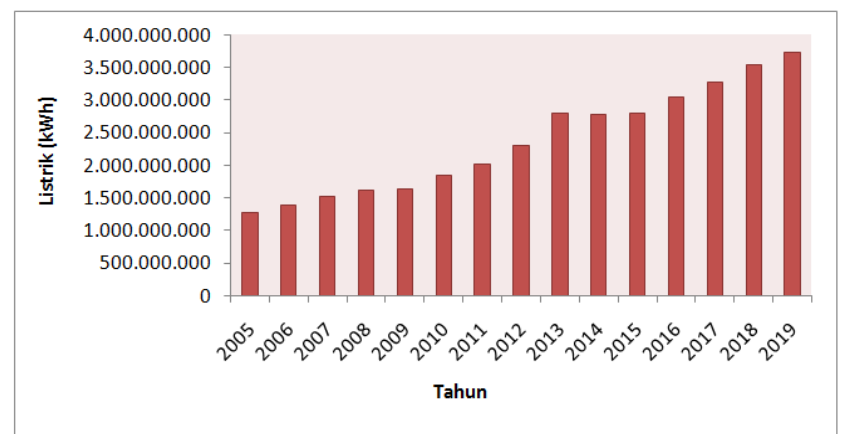

Gambar 4 Data Infrastruktur Listrik 2005-2019 Sumber: BPS Jawa Timur 2020 (data diolah)

Berdasarkan gambar 4.2 diatas terlihat bahwa perkembangan infrastruktur listrik Kabupaten Sidoarjo dari tahun 2005 sampai 2019 mengalami fluktuasi, dengan rata-rata dari tahun 2005 hingga 2019 sebesar 2.372.934.524 miliar kWh/kapita. Perkembangan Infrastruktur Listrik tertinggi tahun 2019 sebesar 3.726.480.000 miliar $\mathrm{kWh} / \mathrm{kapita}$ dan yang terendah tahun 2005 sebesar 1.276.568.996 miliar kWh/kapita. Perkembangan Infrastruktur Listrik Kabupaten Sidoarjo terjadi penurunan pada tahun 2014 sebesar -18.817.519 juta $\mathrm{kWh}$. Penurunan energi listrik yang terjual pada tahun 2014 dikarenakan oleh adanya pemadaman listrik bergilir yang dilakukan oleh PT.PLN.

\section{Data Infrastruktur Jalan}

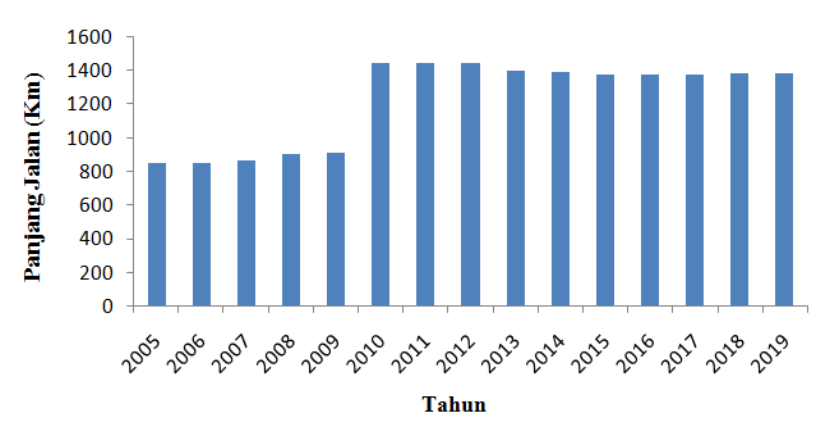

Gambar 5 Data Infrastruktur Jalan 2005-2019

Sumber: BPS Jawa Timur 2020 (data diolah)

Berdasarkan gambar 5 diatas terlihat bahwa perkembangan infrastruktur jalan Kabupaten Sidoarjo dari tahun 2005 sampai 2019 mengalami peningkatan, dengan rata-rata dari tahun 2005 hingga 2019 sebesar $1.221,66 \mathrm{Km} /$ kapita. Peningkatan infrastruktur jalan tertinggi pada tahun 2010 sebesar 1.441,84 km/kapita yang disebabkan adanya penambahan jalan baru guna sebagai rencana pengembangan permukiman. Sedangkan pada tahun 2013 hingga 2019 mengalami penurunan yang disebabkan oleh adanya kerusakan jalan yang belum diperbaiki oleh Pemerintah.

\section{Data Infrastruktur Kesehatan}

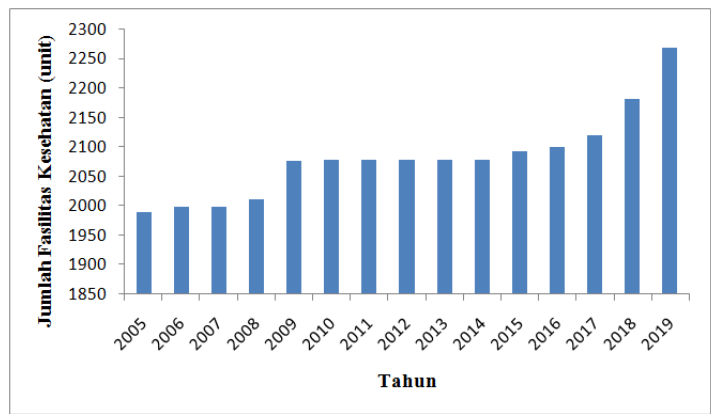

Gambar 6 Data Infrastruktur Kesehatan 2005-2019

Sumber: BPS Jawa Timur 2020 (data diolah)

Pada gambar 6 diatas dapat dilihat data jumlah fasilitas kesehatan dari tahun 2005 hingga tahun 2019 bahwa jumlah fasilitas kesehatan setiap tahunnya mengalami peningkatan tetapi tidak signifikan. Dari data tersebut diketahui ketersediaan jumlah fasilitas kesehatan paling banyak adalah tahun 2019 sebanyak 2267 unit fasilitas kesehatan. Karena kesehatan merupakan investasi penting untuk mendukung pembangunan ekonomi serta dapat meningkatkan angka harapan hidup masyarakat sebagai penunjang 
Yurike Aldona, Wiwin Priana Primandhana dan Muhammad Wahed, Analisis Pengaruh Infrastruktur Listrik, Jalan Dan Kesehatan Terhadap Produk Domestik Regional Bruto Di Kabupaten Sidoarjo

meningkatnya kesejahteraan masyarakat melalui peningkatan jumlah fasilitas kesehatan.

\section{Hasil Analisis Regresi Linier Berganda}

Dalam penelitian ini digunakan analisis regresi linier berganda dan untuk mengolah data yang ada digunakan alat bantu komputer dengan program SPSS (Statistic Program For Social Science). Untuk mencari persamaan linier berganda. Dari perhitungan yang ada didapatkan koefisen-koefisien dan diperoleh persamaan linier bergandanya.

$Y=-109212910,640+0,28 X_{I}+12867,205 X_{2}+$ $\mathbf{5 8 1 2 6 , 9 1 7} X_{3}$

Berdasarkan persamaan diatas, maka dapat dijelaskan melalui penjelasan sebagai berikut:

$\beta_{0}=$ Nilai Konstanta sebesar 109212910,640 menunjukkan apabila Infrastruktur Listrik (X1), Infrastruktur Jalan (X2) dan Infrastruktur Kesehatan (X3) dianggap konstan maka Produk Domestik Regional Bruto di Kabupaten Sidoarjo (Y) akan turun sebesar 109212910,640 juta rupiah.

$\beta_{1}=0,28$ menunjukkan apabila Infrastruktur Jalan (X2) dan Infrastruktur Kesehatan (X3) dianggap konstan, setiap Infrastruktur Listrik (X1) yang digambarkan oleh rata-rata Energi Listrik yang terjual naik satu tahun maka Produk Domestik Regional Bruto di Kabupaten Sidoarjo (Y) akan naik sebesar 0,28 juta rupiah.

$\beta_{2}=12867,205$ menunjukkan apabila Infrastruktur Listrik (X1) dan Infrastruktur Kesehatan (X3) dianggap konstan, setiap Infrastruktur Jalan (X2) yang naik satu kilometer maka tingkat Produk Domestik Regional Bruto di Kabupaten Sidoarjo (Y) akan naik sebesar 12867,205 juta rupiah.

$\beta_{3}=58126,917$ menunjukkan apabila Infrastruktur Listrik (X1) dan Infrastruktur Jalan (X2) dianggap konstan, setiap Infrastruktur Kesehatan (X3) yang digambarkan oleh Jumlah Fasilitas kesehatan naik satu tahun maka Produk Domestik Regional Bruto di Kabupaten Sidoarjo (Y) akan naik sebesar 58126,917 juta rupiah.

\section{Hasil Uji Asumsi Klasik (BLUE/ Best Linier Unbiased Estimator) \\ Uji Autokorelasi}

Penelitian ini dilakukan uji autokorelasi dan didapat nilai uji DW sebesar 1,307. Jumlah data atau (n) ialah 15 dengan jumlah variabel bebas atau (k) yaitu 3, dengan demikian nilai $D W$ tabelnya adalah $(\mathrm{dL}=0,8140$ dan $\mathrm{dU}=1,7501$ ). Oleh Karena itu dijelaskan nilai $D W$ test posisinya berada diantara nilai $\mathrm{dL}$ sampai $\mathrm{dU}$, dengan demikian data yang dipakai dalam penelitian berada didaerah keragu-raguan atau tidak terkena gejala autokorelasi dan dapat digunakan untuk melakukan pengujian seanjutnya.

\section{Uji Multikolinieritas}

Setelah dilakukan uji multikolinieritas didapatkan nilai VIF sebagai berikut nilai VIF infrastruktur listrik $(5,559)$, infrastruktur jalan (2,313), infrastruktur kesehatan (4,289). Adapun hasil tersebut menjelaskan VIF-nya semua Variabel bebas kurang dari 10 sehingga dalam model tidak terkena atau terbebas gejala multikolinieritas.

\section{Uji Heterokedastisitas}

Hasil dari penelitian menunjukkan untuk variabel terikat PDRB, signifikansi koefisien korelasi rank spearman total residualnya lebih dari 0,05 (tidak signifikan) yaitu $\mathrm{X} 1(0,704), \quad \mathrm{X} 2(0,904), \quad \mathrm{X} 3(0,837)$ sehingga tidak terdapat hubungan antar variabel bebas $(\mathrm{X})$, dengan demikian pada model ini lolos dari uji heterokedastisitas.

Berdasarkan hasil pengujian Asumsi Klasik yang sudah diselesaikan diatas, dapat ditarik kesimpulan tidak terjadi pelanggaran asumsi klasik pada model pengamatan ini, sehingga bisa dilanjutkan keanalisis lebih selanjutnya.

\section{Uji Koefisien Determinasi $\left(\mathbf{R}^{2}\right)$}

Hasil pengolahan data tersebut diketahui nilai koefisien determinasi ialah 0,986 yang merupakan 98,6\% dari semua pengamatan, hal ini memperlihatkan Variabel bebas Infrastruktur Listrik (X1), Infrastruktur Jalan (X2), dan Infrastruktur Kesehatan (X3) dapat menjelaskan Variabel dependen PDRB (Y), sedangkan sisanya $1,4 \%$ dijelaskan oleh faktor yang tidak ditampilkan dalam model.

\section{Uji F}

Pengaruh simultan atau bersama-sama dipakai uji $\mathrm{F}$ guna melihat pengaruh atau korelasinya, nilai $\mathrm{F}$ hitung 257,449 signifikasinya 0,000 dengan ukuran signifikasinya $5 \%$ atau $(\alpha=0,05)$, dengan demikian nilai signya $0,000<0,05$. F tabel dengan derajat kebebasan (df1) bernilai 3 (jumlah variabel bebas/k), df2 bernilai 11 (n-k-1) didapatkan nilai $\mathrm{F}$ tabel 3,59 , sehingga $\mathrm{H} 0$ ditolak dan $\mathrm{Hi}$ diterima, oleh karenanya diketahui Infrastruktur Listrik, infrastruktur jalan dan infrastruktur kesehatan secara bersama-sama memiliki hubungan/pengaruh positif terhadap PDRB di Kabupaten Sidoarjo tahun 2005-2019.

\section{Uji t}

Uji t digunakan untuk melihat pengaruh variabel $\mathrm{X}_{1}$ (Infrastruktur Listrik), $\mathrm{X}_{2}$ (Infrastruktur Jalan) dan $\mathrm{X}_{3}$ (Infrastruktur Kesehatan) terhadap variabel Y (Produk Domestik Regional Bruto) secara parsial dengan nilai signifikan sebesar 0,05 .

Pengukuran tabel uji t ini dilihat nilai t hitung 9,227 dengan signifikasi 0,000 , sedangkan untuk nilai $t$ tabel didapatkan dari (df) 11 (n-k-1) dengan hasil 2,201. Sehingga diketahui $\mathrm{t}$ hitung 9,227 $\geq \mathrm{t}$ tabel 2,201 sehingga H0 ditolak dan Hi diterima, kemudian untuk 
signifikansi $0,00<0,05$. Maka untuk Infrastruktur Listrik pengaruhnya signifikan terhadap PDRB di Kabupaten Sidoarjo.

Dari hasil tabel uji $\mathrm{t}$ ini didapatkan nilai $\mathrm{t}$ hitung 2,063 dengan signifikasi 0,064, sedangkan untuk nilai $t$ tabel didapatkan dari (df) 11 (n-k-1) dengan hasil 2,201. Sehingga diketahui $\mathrm{t}$ hitung 2,063 $\leq \mathrm{t}$ tabel 2,201 sehingga $\mathrm{HO}$ diterima dan $\mathrm{Hi}$ ditolak, kemudian untuk signifikansi $0,064>0,05$. Maka untuk variabel Infrastruktur Jalan pengaruhnya tidak signifikan terhadap PDRB di Kabupaten Sidoarjo.

Pengukuran tabel uji $t$ ini didapatkan nilai t hitung 1,945 dengan signifikasi 0,078 , sedangkan untuk nilai t tabel didapatkan dari (df) 11 (n-k-1) dengan hasil 2,201. Sehingga diketahui $\mathrm{t}$ hitung 1,945 $\geq \mathrm{t}$ tabel 2,201 sehingga $\mathrm{H} 0$ diterima dan Hi ditolak, kemudian untuk signifikansi $0,078>0,05$. Maka untuk variabel infrastruktur kesehatan memiliki pengaruh tidak signifikan terhadap PDRB di Kabupaten Sidoarjo.

\section{Pembahasan \\ Pengaruh Infrastruktur Listrik Terhadap Produk Domestik Regional Bruto}

Infrastruktur listrik memiliki pengaruh yang signifikan atau pengaruhnya besar terhadap produk domestik regional bruto (PDRB) di Kabupaten Sidoarjo selama periode 2005 hingga 2019. Sehingga dari hasil penelitian ini dapat dikatakan sesuai dengan peneliti sebelumya (Widianingtyas, 2018), (Maslahah, 2018), (Wibowo, 2016), (Lestari, 2019), (Pratiwi, 2019) yang menjelaskan bahwa infrastruktur listrik berpengaruh signifikan terhadap PDRB. Listrik di era modern saat ini dapat dianggap menjadi salah satu kebutuhan pokok hidup manusia. Hampir semua aktivitas manusia saat ini sudah sangat begantung kepada berbagai peralatan elektronik yang membutuhkan listrik sebagai sumber energinya (Wibowo, 2016). Menurut data dari PT. PLN dalam (BPS, 2018) menunjukkan bahwa kebutuhan masyarakat akan listrik setiap tahun terus bertambah, baik dari jumlah konsumennya maupun tingkat pemakaian listriknya $(\mathrm{KWH})$.

\section{Pengaruh Infrastruktur Jalan Terhadap Produk Domestik Regional Bruto}

Infrastruktur jalan tidak terdapat pengaruh yang signifikan atau pengaruhnya tidak besar terhadap produk domestik regional bruto (PDRB) di Kabupaten Sidoarjo selama periode 2005 hingga 2019. Sehingga dari hasil penelitian ini dapat dikatakan sesuai dengan peneliti sebelumya (Sumadiasa et al., 2016), (Lestari, 2019), (Pratiwi, 2019) menjelaskan bahwa infrastruktur jalan tidak berpengaruh signifikan terhadap PDRB. Kondisi infrastruktur jalan dapat menentukan kelancaran kegiatan ekonomi di suatu tempat, infrastruktur jalan yang baik dan memadai akan mengurangi biaya transaksi dan distribusi barang dan jasa, lama waktu dan bahan bakar yang digunakan akan lebih hemat (Maqin, 2011), sehingga dengan adanya perbaikan infrastruktur yang memadai maka kegiatan transaksi dan distribusi perekonomian di Kabupaten Sidoarjo akan lebih efisien yang pada akhirnya harga barang dan jasa tersebut di pasar akan lebih kompetitif.

\section{Pengaruh Infrastruktur Kesehatan Terhadap Produk Domestik Regional Bruto}

Infrastruktur kesehatan tidak terdapat pengaruh yang signifikan atau pengaruhnya tidak besar terhadap produk domestik regional bruto (PDRB) di Kabupaten Sidoarjo selama periode 2005 hingga 2019. Hasil penelitian ini sejalan dengan penelitian yang dilakukan oleh (Zamzami, 2014), menjelaskan bahwa infrastruktur kesehatan berpengaruh positif tetapi tidak signifikan terhadap Produk Domestik Regional Bruto (PDRB). Kesehatan merupakan pondasi dari kualitas dan kinerja sumber daya manusia dalam suatu wilayah. Tingkat kesehatan sumber daya manusia yang rendah akan semakin menurunkan output yang dihasilkan dari suatu negara baik secara jumlah maupun kualitas yang akhirnya berdampak pada turunnya pertumbuhan ekonominya. Salah satu upaya negara untuk menjaga kesehatan penduduknya adalah dengan menjamin ketersediaan infrasruktur kesehatan bagi seluruh masyarakatnya (Wibowo, 2016).

\section{SIMPULAN}

Dari berbagai teori, hasil dan pembahasan yang telah dijelaskan sehingga peneliti dapat mengambil kesimpulan sebagai berikut:

1. Infrastruktur Listrik, Infrastruktur Jalan, dan Infrastruktur Kesehatan secara simultan berpengaruh nyata signifikan terhadap Produk Domestik Regional Bruto di Kabupaten Sidoarjo.

2. Infrastruktur Listrik berpengaruh signifikan terhadap PDRB Kabupaten Sidoarjo, Hal tersebut digambarkan dengan meningkatnya kebutuhan masyarakat akan listrik setiap tahun terus bertambah, baik dari jumlah konsumennya maupun tingkat pemakaian listriknya (KWH). Ketersediaan energi listrik yang tercukupi bagi para pelaku industri dan usaha dapat memajukan sektor ekonomi yang akhirnya dapat meningkatkan Produk Domestik Regional Bruto di Kabupaten Sidoarjo.

3. Infrastruktur Jalan tidak berpengaruh signifikan terhadap PDRB Kabupaten Sidoarjo, Hal ini disebabkan karena kuantitas dan kualitas jalan yang digunakan masyarakat semakin menurun atau tidak memadai. Sehingga tidak mampu mendukung kegiatan perekonomian Kabupaten Sidoarjo, ketersedian jalan akan meminimalkan modal sehingga proses produksi, distribusi serta jasa akan lebih efektif dan efisien.

4. Infrastruktur Kesehatan tidak berpengaruh signifikan terhadap PDRB Kabupaten Sidoarjo, Hal tersebut dikarenakan tidak semua pengguna fasilitas 
Yurike Aldona, Wiwin Priana Primandhana dan Muhammad Wahed, Analisis Pengaruh Infrastruktur Listrik, Jalan Dan Kesehatan Terhadap Produk Domestik Regional Bruto Di Kabupaten Sidoarjo

kesehatan merupakan usia produktif yang berhubungan langsung dengan peningkatan PDRB, seperti adanya balita, anak-anak, remaja serta lansia yang tidak melakukan kegiatan produksi maupun jasa yang tidak memiliki pengaruh langsung terhadap PDRB.

\section{Keterbatasan Penelitian}

1. Peneliti hanya mengambil tiga variabel bebas yaitu Infrastruktur Listrik, Infrastruktur Jalan, dan Infrastruktur Kesehatan sedangkan masih terdapat faktor-faktor lain yang menjadi penyebab meningkat atau menurunnya Produk Domestik Regional Bruto di Kabupaten Sidoarjo.

2. Selama melakukan penelitian, peneliti menghadapi keterbatasan data, diharapkan Pemerintah Kabupaten Sidoarjo khususnya BPS Kabupaten Sidoarjo untuk melakukan pembaharuan data secara berkala dan mempublikasikan data tersebut agar memudahkan kalangan akademis dalam melakukan evaluasi atau penelitian.

\section{Implikasi dan Saran}

Berdasarkan kesimpulan di atas, maka berikut ini beberapa saran sebagai bahan pertimbangan sebagai berikut :

1. Untuk menaikkan Produk Domestik Regional Bruto di Kabupaten Sidoarjo maka pemerintah diharapkan membuat perencanaan dalam mengeluarkan anggaran lebih untuk memperbaiki kuantitas jalan, seperti perluasan jalan dan penambahan panjang jalan. Pembangunan infrastruktur jalan sebaiknya juga memperhatikan peningkatan kualitas jalan, bukan hanya menambah panjang jalan semata. Pemeliharaan dan peningkatan kualitas infrastruktur jalan harus lebih diperhatikan lagi, terutama bagi jalan yang menghubungkan daerah-daerah yang menjadi pusat perekonomian. Dari hasil penelitian ini terlihat peningkatan panjang jalan saja tidak berperan signifikan dalam meningkatkan produk domestik regional bruto di Kabupaten Sidoarjo.

2. Meningkatkan sarana kesehatan agar lebih mudah mengkases pelayanan kesehatan kepada masyarakat. Meningkatkan upaya pencegahan, pemberantasan dan pengendalian penyakit menular serta tidak menular dengan membuat sadar masyarakat akan pentingnya kesehatan. Dan meningkatkan kualitas dan kuantitas tenaga kesehatan.

3. Untuk penelitian selanjutnya diharapkan menggunakan alternatif variabel penelitian selain infrastruktur listrik, infrastruktur jalan, infrastruktur kesehatan serta penggunaan data sekunder yang lebih besar dan rentang waktu pengamatan diharapkan dapat lebih menggeneralisasi hasil penelitian serta memberikan kesimpulan dan hasil yang lebih komprehensif.

\section{DAFTAR PUSTAKA}

Arindini, U. S. (2018). PENGARUH PEMBANGUNAN INFRASTRUKTUR JALAN, LISTRIK DAN PMA TERHADAP PDRB DAERAH ISTIMEWA YOGYAKARTA PERIODE TAHUN 2004-2016. Interciencia, 489(20), 313-335.

Azwar, S. (2004). Metode Penelitian. Pustaka Pelajar.

BPS. (2018). Statistik Daerah Kabupaten Sidoarjo. In dataku.sidoarjokab.go.id (Vol. 4, Issue 3). dataku.sidoarjokab.go.id.

http://dataku.sidoarjokab.go.id/UpDown/pdfFile/2 01922.pdf

BPS. (2020). Produk Domestik Regional Bruto Atas Dasar Harga Konstan 2010 Provinsi Jawa Timur Berbagai Tahun Terbitan. BPS Jawa Timur.

Dewi, N., \& Sutrisna, I. (2015). Pengaruh Investasi Dan Ekspor Terhadap Penyerapan Tenaga Kerja Melalui Pertumbuhan Ekonomi. E-Jurnal Ekonomi Pembangunan Universitas Udayana, 4(6), 621-636.

Diwan. (2015). PENGARUH PEMBANGUNAN INFRASTRUKTUR TERHADAP PERTUMBUHAN EKONOMI DI KABUPATEN ACEH BARAT. 53(9), 1689-1699. http://publications.lib.chalmers.se/records/fulltext/ 245180/245180.pdf\%0Ahttps://hdl.handle.net/20.

500.12380/245180\%0Ahttp://dx.doi.org/10.1016/j .jsames.2011.03.003\%0Ahttps://doi.org/10.1016/j. gr.2017.08.001\%0Ahttp://dx.doi.org/10.1016/j.pre camres.2014.12

Hapsari, T. (2011). PENGARUH INFRASTRUKTUR TERHADAP PERTUMBUHAN EKONOMI DI INDONESIA. Jurnal Fisip Umrah, Vol 1 No.(1), 287-295.

http://ejournal.usd.ac.id/index.php/LLT\%0Ahttp://jurnal. untan.ac.id/index.php/jpdpb/article/viewFile/1134 5/10753\%0Ahttp://dx.doi.org/10.1016/j.sbspro.20 15.04.758\%0Awww.iosrjournals.org

Jhingan, M. . (2008). Ekonomi Pembangunan dan Perencanaan. Raja Grafindo.

Kuncoro, M. (1997). Ekonomika Pembangunan: Teori, Masalah dan Kebijakan. Unit Penerbit dan Percetakan STIM YKPN.

Lestari, E. T. P. (2019). ANALISIS PENGARUH INFRASTRUKTUR JALAN, INFRASTRUKTUR KESEHATAN, DAN INFRASTRUKTUR LISTRIK TERHADAP PRODUK DOMESTIK REGIONAL BRUTO DI KABUPATEN GRESIK.

Maqin, A. (2011). Pengaruh Kondisi Infrastruktur Terhadap Pertumbuhan Ekonomi di Jawa Barat. Trikonomika, 10(1), 10-18.

Maslahah, L. (2018). PENGARUH INFRASTRUKTUR TERHADAP PERTUMBUHAN EKONOMI DI KABUPATEN PONOROGO. Jurnal Ekonomi.

Pratiwi, R. F. (2019). ANALISIS PENGARUH INFRASTRUKTUR JALAN, LISTRIK DAN AIR TERHADAP PRODUK DOMESTIK REGIONAL 
Yurike Aldona, Wiwin Priana Primandhana dan Muhammad Wahed, Analisis Pengaruh Infrastruktur Listrik, Jalan Dan Kesehatan Terhadap Produk Domestik Regional Bruto Di Kabupaten Sidoarjo

BRUTO DI KOTA SURABAYA.

Putro, N. S. (2011). PENGARUH PERTUMBUHAN EKONOMI, PENDAPATAN ASLI DAERAH dan DANA ALOKASI UMUM TERHADAP PENGALOKASIAN ANGGARAN BELANJA MODAL (STUDY KASUS PADA KABUPATEN/KOTA DI PROVINSI JAWA TENGAH). Universitas Diponegoro Semarang, $1-63$.

Situmorang, A. T. (2011). Pengaruh Efisiensi Perekonomian Terhadap Pertumbuhan Ekonomi 32 Provinsi Di Indonesia. 1-28.

Sumadiasa, I., Tisnawati, N., \& Wirathi, I. (2016). Analisis Pengaruh Pembangunan Infrastruktur Jalan, Listrik Dan Pma Terhadap Pertumbuhan Pdrb Provinsi Bali Tahun 1993-2014. E-Jurnal Ekonomi Pembangunan Universitas Udayana, 5(7), 925-947.

Wibowo, A. B. L. (2016). Pengaruh Infrastruktur Ekonomi dan Sosial Terhadap Pertumbuhan Ekonomi Di Indonesia Tahun 2006 - 2013. Skripsi Fakultas Ekonomi Universitas Negeri Yogyakarta, $1-135$.

Widianingtyas, F. (2018). PENGARUH INFRASTRUKTUR EKONOMI DAN SOSIAL TERHADAP PERTUMBUHAN EKONOMI DI WILAYAH JAWA DAN SUMATERA TAHUN

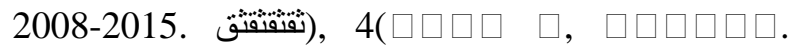
https://www.jstage.jst.go.jp/article/amr/1/5/1_010 501/_article/-

char/ja/\%0Ahttp://www.ghbook.ir/index.php?nam

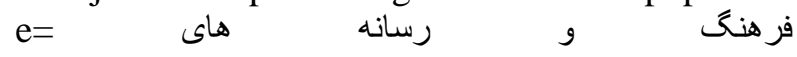
نوين \&option=com_dbook\&task=readonline\&book $\_$id $=13650 \&$ page $=73 \&$ chkhashk $=$ ED9C9491B4\& Itemid=218\&lang=fa\&tmpl=component\%0Ahttp:/ $/ \mathrm{dx}$.

World Health Organization. (2013). Kesehatan Mental dalam Kedaruratan. Jurnal Kependudukan Indonesia, 8(1), 37-52. http://ejurnal.kependudukan.lipi.go.id/ojs248jki/in dex.php/jki/article/download/21/15.

Zamzami, F. (2014). Analisis Pengaruh Infrastruktur Terhadap PDRB Jawa Tengah Tahun 2008 2012. Skripsi Fakultas Ekonomi Dan Bisnis Universitas Diponegoro, 1-60. 